\title{
PERSONAL INVESTMENT IN JAPAN AND THE U.S.A.: A STUDY OF WORKER MOTIVATION
}

\author{
DAVID W. SHWALB and BARBARA J. SHWALB \\ Westminster College of SLC, University of Utah
}

DELWYNL. HARNISCH

University of Illinois

MARTIN L. MAEHR

University of Michigan

KIYOSHI AKABANE

Tokyo University

\begin{abstract}
The Inventory of Personal Investment (IPI) was administered to 522 Japanese and 746 American workers to compare their work motivation and self-concepts. Eleven subscales were formed based on the IPI model and were found through factor analysis to be appropriate for the samples in both countries. Discriminant analyses of scale scores by subjects' nationality, gender, occupational strata, and age are reported. Findings included: (1) Japanese and American workers sampled emphasized different aspects of meaning as they perceive work and self, (2) Japanese and American women sampled exhibited similar profiles to one another, as did the two male subsamples, and (3) motivational profiles for various age groupings differed between the two samples. The results are related to previous research on Japanese and American workers.
\end{abstract}

The following individuals are gratefully acknowledged: Jun Nakazawa, Kanae Miura, Hiroshi Azuma, Hisao Nomura, Kazuhiro Tanaka, Yotaro Inoue, Seisoh Sukemune, Toshiaki Naitoh, Yukio Hirakoshi, Masako Bunden, Eijiro Tanaka, Masahiko Miyake, Kunihiko Taniguchi, Fumiko Omoto, Masayoshi Waseda, Shoji Nakano, Shigeru Miyake, Setsuko Suyama, Yoshiharu Ogaki, Hiroo Masuda, Tsutomu Yamashita, Etsuo Kitahara, and Larry Braskamp.

The first author was supported by a Fulbright Department of Education fellowship at the time of the study, and the second author by a Japanese Ministry of Education fellowship.

Reprint requests should be sent to B. Shwalb, Koryo International College, Sagamine, Nisshin-cho, Aichi-ken, 470-01 Japan. 
Work is a highly significant activity for most individuals in modern societies (England \& Misumi, 1986), and work settings have long been a popular focus of psychological research. It is also recognized that intercultural studies contribute to an understanding of worker psychology, because work has different value and different effects across societies (Hofstede, 1983). Outside the United States, few societies have aroused greater interest in this area than Japan. The economic accomplishments of the Japanese have prompted doubts about the condition of the work ethic in the United States (Vogel, 1985) and stimulated years of scrutinizing the Japanese "miracle."

Social science research from the 1980 s on differential work and achievement orientations in Japan and the U.S. has gone far to alleviate previous misunderstanding. Recent comparative studies indicate both important psychological similarities and differences. For the most part, work is highly valued (England \& Misumi, 1986) in both societies, but it is defined somewhat differently by national samples of Japanese and Americans (England \& Harpaz, in press). In England and Harpaz's study, people in both cultures defined work primarily (1) as a way to earn money, (2) as a way of producing something of value, and (3) as the execution of a task or project. But $50 \%$ of Japanese workers and only $24 \%$ of Americans stressed the importance of work as "something for which one is accountable," whereas $31 \%$ of Americans and only $7 \%$ of Japanese employees defined work as giving one a "feeling of belonging." These data indicate that in some ways (e.g., emphasizing financial gain) Americans and Japanese perceive work similarly, whereas in other ways (e.g., concerning accountability or affiliation) work has a different meaning in the two societies. The present exploratory study examines these patterns further, from the perspective of a theory of motivation.

In addition to comparisons of samples from two societies, this investigation considers the effects of three subject characteristics on motivation: gender, occupational classification, and age. Previous comparative research has indicated that these variables are sources of intracultural variation. First, Japanese and American women appear to have different career patterns and work orientations from men and from each other (Lebra, 1984; McLendon, 1983). Second, the research of Schooler and his colleagues (e.g., Naoi \& Schooler, 1985) has shown that characteristics of one's job (including status and degree of self-directedness) have differential psychological effects on Japanese and American workers. Third, from a lifespan view of occupational devclopment, work may be experienced differently at each stage of career development in the two societies (Osako, 1986). The Western perception of a homogeneous Japanese work force is an ethnocentric myth (Dale, 1986), and so the data reported here include variation within each cultural sample. 


\section{Personal Investment Theory}

This study was formulated in terms of personal investment theory, detailed by Maehr and Braskamp (1986). Summarized briefly, the theory of personal investment is a cognitive approach to motivation focusing on the subjective meaning of situations to individuals. This "meaning," which determines how a person behaves or chooses to invest time and energy, consists of the individual's perception of one's goals, self, and alternatives.

Personal incentives are an individual's conscious or unconscious goals, and can be assigned to four categories: task incentives, ego incentives, social incentives, and extrinsic rewards. People who hold task incentives are concerned primarily with the task at hand, find tasks intrinsically absorbing, or at least want to achieve personal standards of excellence. Ego incentives refer to the competitive desire to perform well in comparison to other people. People who hold social incentives are concerned with affiliation, gaining power, social solidarity, pleasing others, or showing social concern. Finally, the promise of extrinsic rewards, such as financial rewards or social recognition, acts as an incentive for some people.

The second facet of meaning, sense of self, is the collection of beliefs and feelings about who one is. It encompasses the aspects of sense of identity that come with feelings of self-reliance, the tendency to set goals, and judgments about oneself as instrumentally competent. The third facet of meaning, perceived options, refers to the behavioral alternatives a person perceives to be available. Since perception of options (e.g., job opportunities) are situationally based, this third aspect of meaning could not be reliably assessed by the self-report instrument used here. Therefore, we focused on the facets of incentives and self that give meaning to work and have a more trans-situational quality.

The present study addressed three research questions. First, are the same dimensions of Personal Incentives or Sense of Self exhibited in both Japanese and American samples? Second, which dimensions of meaning are emphasized by workers in each sample? Third, how might meanings of Personal Incentives or Sense of Self vary within the two samples according to an individual's occupational status, gender, or age?

\section{METHOD}

\section{Subjects}

Subjects were 746 American and 522 Japanese adults $(M=40$ years, range $=18-79$ years in the U.S.; $M=37$, range $=18-69$ years in Japan). Breakdowns by age groupings were quite similar in the two cultural samples, with two-thirds of Japanese and American respondents under 
age 45. The proportion of females was greater in the American than in the Japanese sample (43\% vs. $29 \%$ ), and Americans reported slightly more education than did Japanese, which coincides with the more frequent utility of postgraduate education in American society.

The largest number of American subjects (60\%) described themselves as "managerial/administrative," whereas in Japan a slim majority described themselves as "clerical/technical" workers. Smaller numbers of self-employed individuals and sales/service workers also were represented. The discrepancy in proportions of job classifications in the two samples is probably due to the use of global job categories. Many Japanese who describe themselves as clerical workers are in fact salarymen (Vogel, 1991), who in the West would be classified as lower-level managers (Furukawa, 1988). In Japan, the title of manager is reserved for a small number of senior employees, although workers in both the U.S. and Japan perform managerial tasks in midcareer. Similarities in mean age and in mean length of current employment further indicated that occupational differences between the two samples were probably minor. Nevertheless, interpretations of data related to occupational category are tentative, and follow-up research must measure job categories with greater sensitivity.

The survey took place in the American midwest, and in six Japanese prefectures (comparable to states in the U.S.). In each sample, the large majority of respondents lived on the outskirts of metropolitan areas. In both Japan and the U.S., 25 personal contacts of the authors distributed questionnaires to co-workers at commercial, government, and educational workplaces. Although this opportunity sampling lacks the scientific veracity of a national random sample (e.g., England \& Harpaz, in press), it did provide a sample from a wide heterogeneity of workplaces and high return rates $(>80 \%)$ in both countries.

\section{The Inventory of Personal Investment}

The instrument used was the Inventory of Personal Investment (IPI, Maehr \& Braskamp, 1986). This instrument evolved out of the abovedescribed model of worker motivation. Copies of the 191-item research form and its latest version, "Spectrum" (in both Japanese and English), are available from the authors upon request. In format and structure, the IPI is similar to instruments commonly employed in attitude and interest surveys. Most IPI items are worded in the positive and presented in two different formats. The first format was used for $70 \%$ of the items, and uses a 5-point Likert scale of strongly disagree to strongly agree (e.g., "I delay immediate reward for long-term goals"). A second format, used for a smaller subset of items, instructs respondents to project their perceptions of successful people from a list of personal characteristics. The respondent rates each characteristic on a 5-point Likert scale, indicating 
the degree to which the characteristic definitely doesn't/definitely does describe his or her idea of a successful person (e.g., "Needs to be number one"; "Likes a challenge"). Such a 5-point Likert scale is typical in Japanese-language survey instruments. Because the IPI was composed of 191 items, subscales were developed for analyses. Table 1 presents sample items and a few main characteristics of the factors represented by each of eight Personal Incentive and three Sense of Self subscales.

To demonstrate the intercultural utility of the IPI, it was first translated into Japanese using standard back-translation procedures by bilingual Japanese who were not familiar with the original instrument. Extensive consultation with Japanese psychologists and pretesting with business people were carried out to ensure the cultural appropriateness of every

\section{TABLE 1}

Definitions of IPI Factors and Sample Item From Each Subscale

\begin{tabular}{|c|c|}
\hline \multicolumn{2}{|l|}{ Personal Incentives } \\
\hline Task & $\begin{array}{l}\text { Like a challenge; totally involved in one's work. "I } \\
\text { like to solve problems." }\end{array}$ \\
\hline Excellence & $\begin{array}{l}\text { Stress self-improvement; enjoy working long } \\
\text { hours. } \\
\text { "I work hard to improve my skills." }\end{array}$ \\
\hline Competition & $\begin{array}{l}\text { Work hard to win; not afraid to beat others. "Win- } \\
\text { ning is important to me." }\end{array}$ \\
\hline Power & $\begin{array}{l}\text { Seek positions of leadership; like to be in control. } \\
\text { "People seek me out for advice." }\end{array}$ \\
\hline Affiliation & $\begin{array}{l}\text { Enjoy being with and helping others, even at own } \\
\text { expense. } \\
\text { "Loyalty to my friends is important to me." }\end{array}$ \\
\hline Social Concern & $\begin{array}{l}\text { Sacrifice personal gains for others and for causes. } \\
\text { "I enjoy helping others even if I have to make some } \\
\text { sacrifices." }\end{array}$ \\
\hline Financial & $\begin{array}{l}\text { Work for monetary rewards and financial status. "I } \\
\text { am happiest when I am making money." }\end{array}$ \\
\hline Recognition & $\begin{array}{l}\text { Like to receive respect, praise, and encourage- } \\
\text { ment. } \\
\text { "I work hard because I want respect from my co- } \\
\text { workers." }\end{array}$ \\
\hline \multicolumn{2}{|l|}{ Sense of Self } \\
\hline Goal-directedness & $\begin{array}{l}\text { Ambitious; willing to postpone gratification; self- } \\
\text { starters. } \\
\text { "I set long-term goals." }\end{array}$ \\
\hline Self-Reliance & $\begin{array}{l}\text { Enjoys working independently on open-ended, dif- } \\
\text { ficult tasks. } \\
\text { "Tasks that I must do by myself are not frightening } \\
\text { to me." }\end{array}$ \\
\hline Sense of Competence & $\begin{array}{l}\text { Confident, self-made, resilient. } \\
\text { "I bounce back quickly from defeat." }\end{array}$ \\
\hline
\end{tabular}


item. As a check on the conceptual equivalence of the IPI for studying American and Japanese workers, factor analyses were conducted on the responses of both cultural groups.

\section{RESULTS}

\section{The Factor Structures of the Japanese and American IPI}

The first research question concerned whether the Personal Incentive and Sense of Self dimensions found with U.S. subjects were the same or similar to those found for Japanese subjects. Confirmatory factor analyses (detailed in Maehr \& Braskamp, 1986) showed that the factor structures of the Japanese and English versions of the IPI were equivalent. All eight of the IPI Personal Incentives and all three Sense of Self categories (in Table 1) were replicated with the Japanese sample. Therefore, Japanese and American respondents could be said to attribute the same meanings to IPI items.

\section{Nationality and Gender Differences}

The second and third research questions concerned whether the Japanese and U.S. samples, or subsamples within either cultural group, differed in their responses to the Personal Incentive or Sense of Self dimensions. A series of multivariate analyses were conducted to determine whether the IPI profiles of the two groups varied by subjects' nationality, gender, job classification, and age group. The results of the first of three discriminant analyses, presented in Table 2, summarize the factors that distinguish the two samples when examined for four groups based on nationality and gender. Figure 1 gives a profile of the country-by-gender means for this discriminant analysis. Two significant functions discriminated maximally between these four groups.

Nationality Differences. The first function differentiated between the Japanese and American workers sampled. The only Personal Incentives scale score that did not contribute to this discriminant function was Competition, and Power was of minimal importance. Generally speaking, it was Japanese subjects' emphasis on the Task, Excellence, and Financial Rewards and Americans' stress on Affiliation, Social Concern, and Recognition that distinguished the two groups. Of the Sense of Self scores, American subjects also placed greater stress on Self-Reliance and Goal-Directedness than did Japanese respondents.

Gender Differences. The second discriminant function distinguished males from females in both countries in a similar manner. Across both 
TABLE 2

Standardized Discriminant Function Weights and Means for Groups Based on Country and Sex

\begin{tabular}{lrr}
\hline & \multicolumn{2}{c}{$\begin{array}{c}\text { Standardized Weights on } \\
\text { Discriminant Functions }\end{array}$} \\
\cline { 2 - 3 } & \multicolumn{1}{c}{ II } \\
\hline Personal Incentives & & \\
Task & -.31 & -.51 \\
Excellence & -.30 & .31 \\
Competition & .06 & .15 \\
Power & .12 & .74 \\
Affiliation & .38 & -.39 \\
Social Concern & .27 & -.06 \\
Recognition & .48 & -.06 \\
Financial & -.40 & .31 \\
Sense of Self & & -.10 \\
Goal-Directedness & .47 & .26 \\
Self-Reliance & .77 & -.03 \\
Sense of Competence & -.15 & .19 \\
Class Means & & .33 \\
U.S. Males & .87 & .29 \\
U.S. Females & .59 & -.53 \\
Japanese Males & -.99 & \\
Japanese Females & -1.19 & \\
\hline
\end{tabular}

the American and Japanese subsamples, males were distinguished by an emphasis on Power, Excellence, Financial Concerns, and, to some degree, Self-Reliance, while female responses stressed Affiliation and Task Incentives.

\section{Occupational Category Differences}

Comparisons between occupational categories are made in light of the difficulty in categorizing job status. Figure 2 shows profiles of Japanese and U.S. occupational groups on the two significant discriminant functions. The class means for these groups are given in Table $\mathbf{3}$, along with the standard weights used in discriminating between the eight groups formed by country and occupational classifications. In both the American and Japanese samples, measures of Personal Investment depended on one's occupation, but the breakdowns into subgroups differed slightly. In the American sample, sales/service workers and owners/executives stressed Power and Financial incentives as well as a Goal-Directed Sense of Self, whereas subjects in the clerical and managerial ranks emphasized 


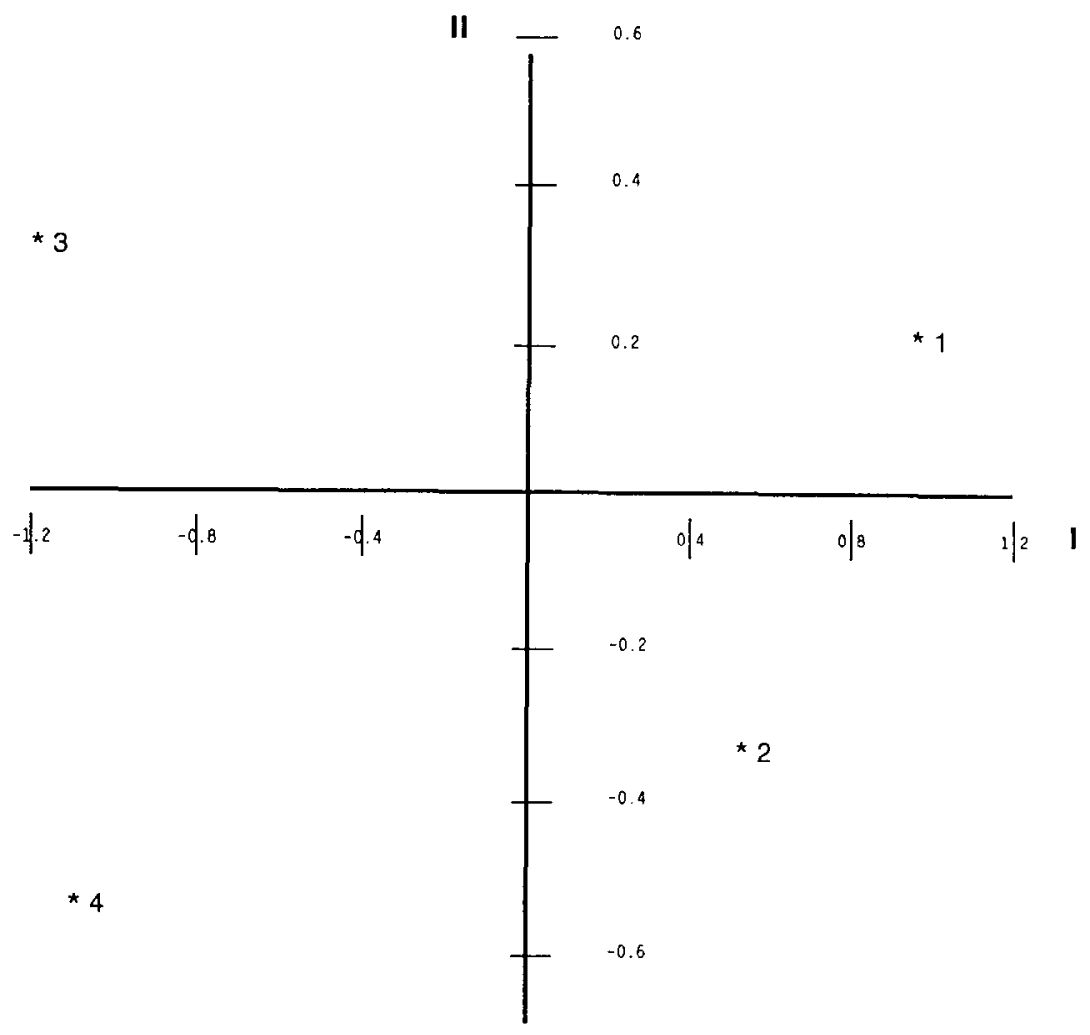

FIGURE 1. Motivational orientations for groups based on country (I) and sex (II). United States: 1 = males, 2 = females; Japan: 3 = males, 4 = females.

Recognition above all else. This was also the case among the Japanese, except that Japanese managers responded more like owners than like their clerical/technical subordinates.

\section{Age Differences}

Comparisons between age groups in Personal Incentives differed between the samples of Japanese and American workers. First, the effects of age among Americans seemed to follow a fairly linear trend-the younger the subject, the greater the emphasis on Affiliation, Financial Rewards, and Sense of Self as Competent. The older the subject, the greater was the stress on Task and Competitive Incentives and on SelfReliance. In the Japanese sample, however, the meanings stressed by different age subgroups were in an opposite direction, with Task and Competitive Incentives and Self-Reliance most important for the 


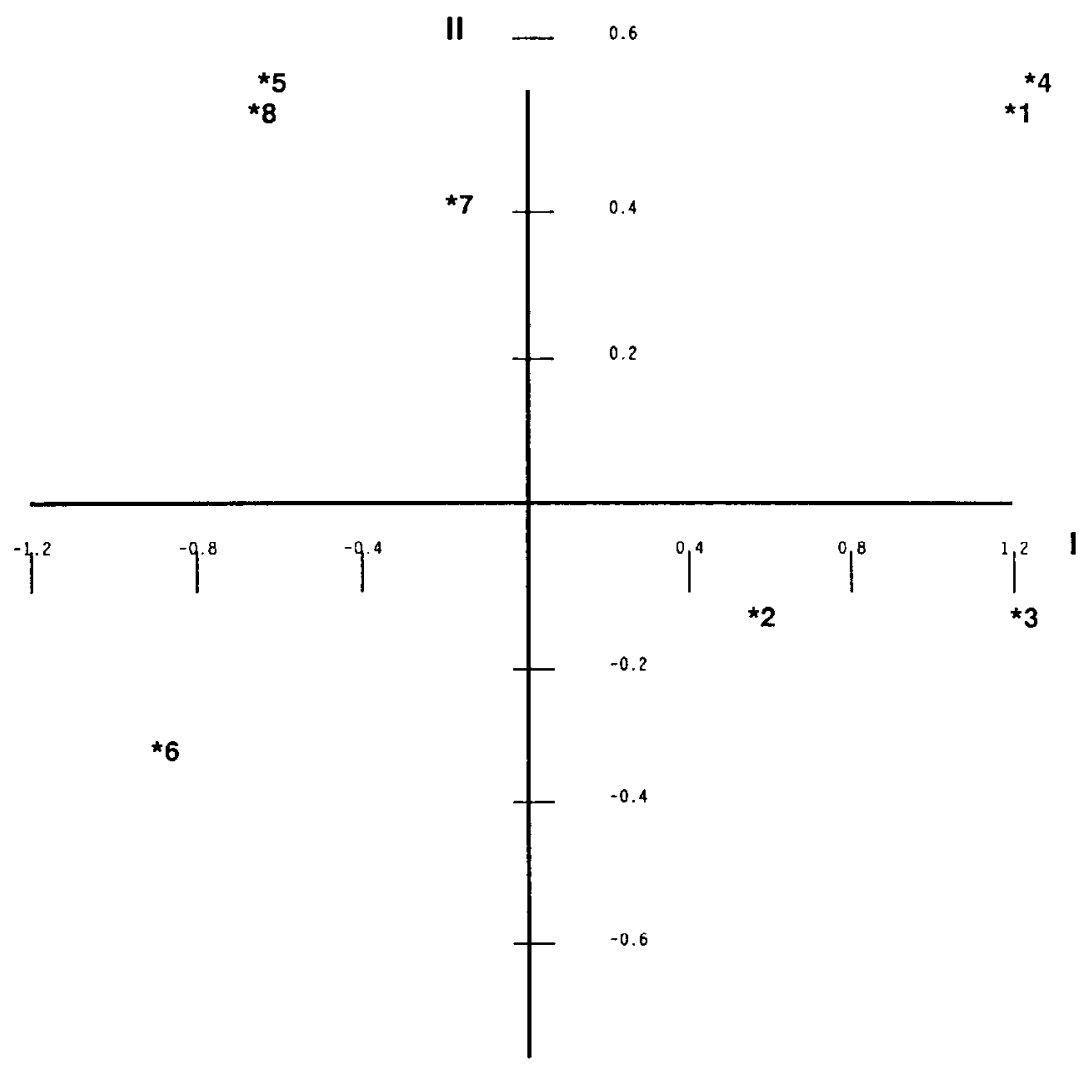

FIGURE 2. Motivational orientations for groups based on country (I) and occupation (II). United States: 1 = sales, service, professional; 2 = clerical, technical; 3 = manager, administrator; 4 = owner, executive; Japan: 5 = sales, service, professional; 6 = clerical, technical; 7 = manager, administrator; $8=$ owner, executive.

youngest Japanese workers, and Affiliation, Financial Rewards, and Competent Self emphasized among middle-aged (36-54-year-old) subjects. The responses of the over-55-year-old Japanese lay between the two extremes. See Figure 3 for a profile of the age-by-country means for the two significant functions summarized in Table 4.

\section{DISCUSSION}

In answer to the main questions posed, (1) the Japanese and American worker samples exhibited the same Personal Incentive and Sense of Self dimensions, (2) workers from the two societies placed different relative 
TABLE 3

Standardized Discriminant Function Weights and Means on Significant Discriminant Functions for Groups Based on Country and Occupational Level

\begin{tabular}{lrr}
\hline & \multicolumn{2}{c}{$\begin{array}{c}\text { Standardized Weights on } \\
\text { Discriminant Functions }\end{array}$} \\
\cline { 2 - 3 } & \multicolumn{1}{c}{$\mathrm{I}$} \\
\hline Personal Incentives & & \\
Task & -.26 & -.24 \\
Excellence & -.37 & .29 \\
Competition & .16 & -.17 \\
Power & .18 & .35 \\
Affiliation & .40 & .10 \\
Social Concern & .26 & -.10 \\
Recognition & .40 & -.63 \\
Financial & -.29 & .53 \\
Sense of Self & & .37 \\
Goal-Directedness & .38 & -.19 \\
Self-Reliance & .79 & -.22 \\
Sense of Competence & -.04 & \\
Class Means & & .50 \\
United States & & -.14 \\
Sales, service, prof. & 1.17 & -.14 \\
Clerical, technical & .61 & .53 \\
Manager, administrator & 1.05 & .53 \\
Owner, executive & 1.33 & .48 \\
Japanese & & .63 \\
$\quad$ Sales, service, prof. & -.85 & \\
Clerical, technical & -.39 & \\
Manager, administrator & -.67 & \\
Owner, executive & & \\
\hline
\end{tabular}

values on these dimensions, and (3) the meanings of Personal Incentives and Sense of Self varied within subgroups of respondents from both societies.

\section{Factor Structure and Conceptual Equivalence}

Berry (1980) states that in order to make cross-cultural comparisons with a psychological instrument, conceptual equivalence (i.e., in the meaning of the stimuli) is required. Factor analyses clearly documented such equivalence here by showing that both Americans and Japanese conceptualized the IPI items using the identical 11 dimensions. This 


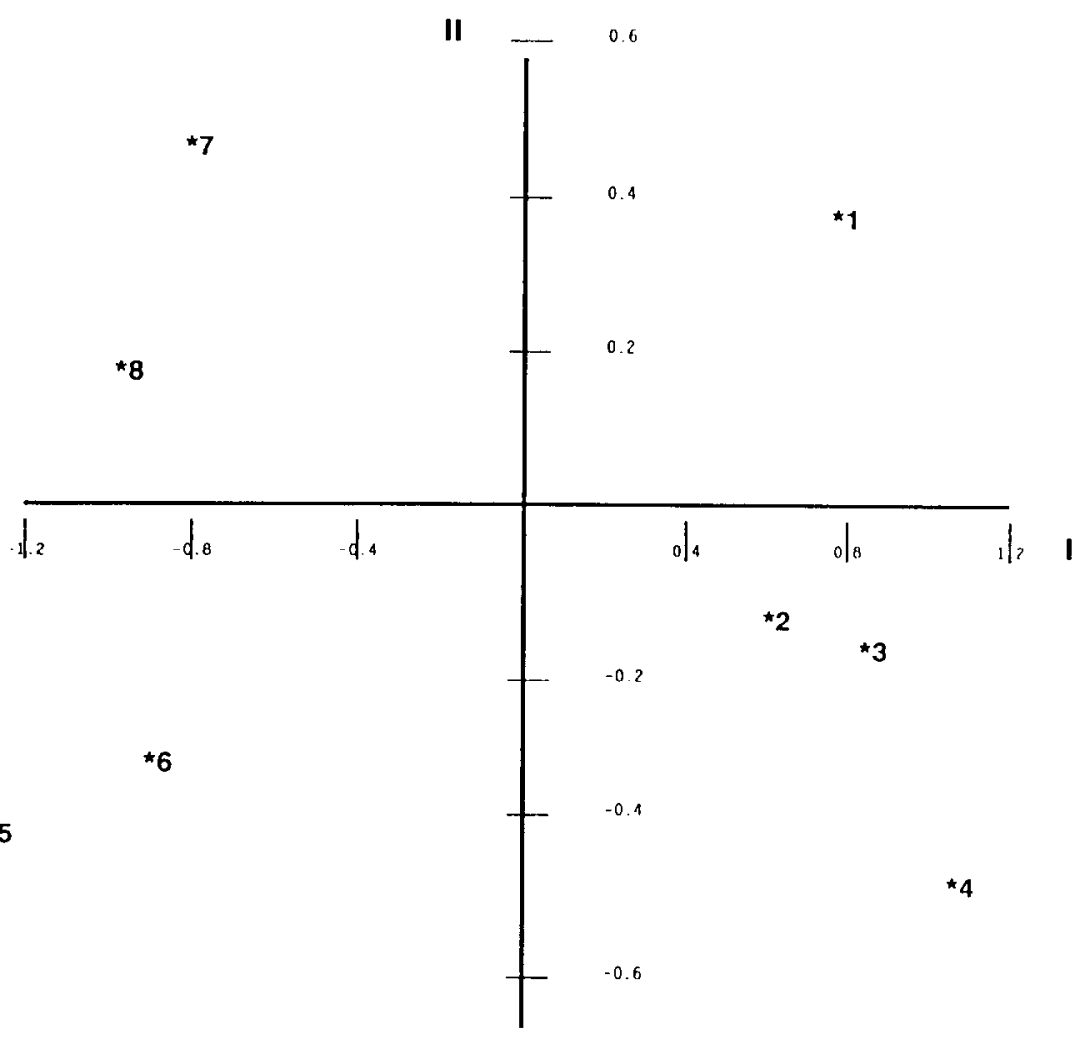

FIGURE 3. Motivational orientations for groups based on country (I) and age (II). United States: $1=35$ and younger, $2=36-44$ years, $3=45-54$ years, $4=55$ and older; Japan: $5=35$ and younger, $6=36-44$ years, $7=45-54$ years, $8=55$ and older.

justified our use of subscale analyses. Whatever differences in Japanese and Amcrican mentality may be suggested clscwhere (c.g., Lcbra, 1976), factor analysis thus indicated significant cross-cultural conceptual overlap.

\section{Nationality Differences}

Personal Incentives. Despite their identical IPI factor structures, the samples of U.S. and Japanese workers exhibited significantly different Personal Incentives and Sense of Self profiles. Personal Incentive scales contributing most to the differentiation between the two countries were Affiliation, Recognition, and Social Concern, with U.S. subjects placing more importance on these personal incentives than the Japanese. The 
TABLE 4

Standardized Discriminant Function Weights and Means on Significant Discriminant Functions for Groups Based on Country and Age Levels

\begin{tabular}{lrr}
\hline & \multicolumn{2}{c}{$\begin{array}{c}\text { Standardized Weights on } \\
\text { Discriminant Functions }\end{array}$} \\
\cline { 2 - 3 } & \multicolumn{1}{c}{ II } \\
\hline Personal Incentives & & \\
Task & -.27 & -.63 \\
Excellence & -.25 & .29 \\
Competition & .06 & -.31 \\
Power & .09 & -.01 \\
Affiliation & .41 & .47 \\
Social Concern & .30 & .06 \\
Recognition & .42 & .07 \\
Financial & -.41 & .54 \\
Sense of Self & & .13 \\
Goal-Directedness & .44 & -.28 \\
Self-Reliance & .77 & .28 \\
Sense of Competence & -.19 & \\
Class Means & & .35 \\
U.S.A. & & -.15 \\
35 and younger & .59 & -.18 \\
36-44 years & .67 & -.46 \\
$45-54$ years & .91 & .03 \\
55 and older & 1.10 & \\
Japanese & & .36 \\
35 and younger & -1.18 & .88 \\
36-44 years & -.88 & \\
$45-54$ years & & \\
55 and older & & \\
\hline
\end{tabular}

Japanese workers exhibited the higher scores on Financial, Task, and Excellence incentives. Power and Competition scales did not discriminate significantly between the two samples. On the basis of McClelland's (1961) work, one might have expected American respondents to exhibit a greater stress on Power and Competition. The view of Japanese as TaskInvolved is in accord with patterns of Japanese socialization through adolescence and with the opinion that Japanese are highly motivated and productivc (Dore \& Sako, 1989; Koshiro, 1983).

The finding of greater emphasis by American respondents on Affiliation replicates England and Harpaz's (in press) finding that Americans are more likely to define work activity in terms of positive personal affect (i.e., a feeling of belonging) than are Japanese. The results for Social Concern are also consistent with those of England and Harpaz (in press) 
and are probably due to the fact that social activism and volunteerism are new phenomena in Japanese society. Overall, the present comparison of the two profiles creates the impression that the Japanese sample is guided by Personal Incentives (Task and Excellence) encouraging a strong achievement orientation.

Sense of Self. Of the Sense of Self factors, Self-Reliance figured most prominently in distinguishing the two cultural samples, with American workers placing considerably more stress on Self-Reliance than Japanese subjects. But how can Americans stress both Self-Reliance and Affiliation? Looking more closely at the items composing these scales, it might be that the Americans sampled prefer to accomplish tasks on their own, even though they like to be with others and want to be recognized for what they do. The Japanese sampled express less interest in social interaction but do not believe that achievement must be an individual accomplishment. Certainly the effect of some Japanese occupations is toward self-direction (Naoi \& Schooler, 1985), and many Japanese are observed to be strongly affiliative, particularly outside of regular working hours.

\section{Gender Differences}

The same discriminant analysis (Table 2 and Figure 1) also revealed that the present sample of Japanese and American women were more similar to each other in their responses to the IPI than they were to men in their respective societies. This supports the notion of a transcultural duality of male and female orientations (Bakan, 1966). In accord with the theory that Western males stress the development of the individual in their thinking, whereas females stress human relationships (Gilligan, 1982), male scores centered on Power, Financial Rewards, and SelfReliance, and female scores centered on Affiliation. Also, McLendon (1983) observed firsthand how organizational constraints seem to preclude most Japanese female employees from achieving power, self-reliance, financial reward, or personal excellence. The female emphasis on Task Involvement is not incongruent with their Affiliation incentives, because women may be especially involved with their work because of their relationships.

\section{Occupational Status Differences}

There was a discrepancy between the two cultural samples in the proportions of workers classified in the form of global job categories, so the following interpretations are made with caution. In both cultures, owners/executives, and sales/service/professional personnel were the occupations most oriented toward Power and Financial Rewards and were GoalDirected. Only in Japan did managers/administrators also follow this 
pattern, whereas clerical/technical workers in both cultures emphasized Social Recognition. This may be due to the greater self-directedness and autonomy expected of Japanese administrators (Furukawa, 1988), who were characterized earlier as a more senior and elite group than their American counterparts. At the least, these data confirm Naoi and Schooler's (1985) point that job status influences one's perceptions of work. Future research should focus on which aspects of managerial work might cause Japanese and American administrators to be motivated differently.

\section{Age Differences}

The youngest Japanese workers sampled (under 35 years) stressed Task Involvement, Competition, and Self-Reliance, which was precisely the pattern for the oldest American respondents. The younger Americans responded in the same manner as did middle-aged (36- to 54-year-old) Japanese, emphasizing Affiliation, Financial Rewards, and a Sense of Self as Competent. Whether these dramatic age-group differences reflect cohort, time-of-measurement, or developmental influences cannot be determined from the present cross-sectional data. It has been shown that younger Americans are likely to postpone career decisions and are skeptical that their jobs can be rewarding (Turner \& Helms, 1989), whereas Japanese youth make earlier occupational commitments and begin careers more loyal to their companies (Lincoln \& Kallenberg, 1990). This could explain the Task Involvement and Competitiveness of the younger Japanese subsample, compared with the emphais on Financial Rewards stressed by younger Americans. But it is more difficult to interpret the views of middle-aged subjects or why the oldest Americans and youngest Japanese workers displayed the same profiles. To begin to explain such variation, subsequent research on worker Personal Incentives and Sense of Self must proceed from a lifespan developmental perspective.

\section{CONCLUSIONS}

The IPI has shown similarities and differences in worker motivation and sense of self between and within samples of Japanese and American workers. At times the results were perplexing. It is often assumed that the two societies' attitudes towards "a woman's place" and "a man's place" are different (Lebra, 1984), but according to the present data, Japanese and American women's meanings attributed to work and self were quite similar. And why did the Japanese administrators sampled, but not the Americans, emphasize Power and Financial Rewards? Why do youngest Japanese workers and oldest American workers value the same incentives?

Multiple measures of behavior, situations, and job performance will be 
necessary in future intercultural research in order to explain the causes and effects of worker motivation. In addition, self-report measures are subject in every culture to problems of social desirability and sets toward testing/measurements. Therefore, intensive research on the reactions of American and Japanese subjects to testing situations in general and to scale-rating procedures in particular are also warranted before proceeding further with the cross-cultural use of the IPI.

Despite such cautions, the present investigation raised some interesting issues. For instance, given the rapid increase of Japanese companies operating in the United States and American business ventures in Japan, it would be valuable to discover more about different motivational patterns in Japanese and American managers. Gender comparisons, in light of the advancing occupational status of women in both Japanese and the U.S., might focus on males and females within specific occupational categories. Additionally, age comparisons should include the longitudinal assessment of Personal Investment within specific occupations to determine cultural differences in career development. The current data show the clear need for further study of intercultural and intracultural variation in worker motivation.

\section{REFERENCES}

BAKAN, D. (1966). The duality of human existence. Chicago: Rand-McNally. BERRY, J. W. (1980). Introduction (pp. 1-28 of Methodology). In H. Triandis \& J. Berry (Eds.), Handbook of cross-cultural psychology (Vol. 2). Boston, MA: Allyn \& Bacon.

DALE, P. N. (1986). The myth of Japanese uniqueness. New York: St. Martin's Press.

DORE, R. P., \& SAKO, M. (1989). How the Japanese learn to work. New York: Routledge.

ENGLAND, G., \& HARPAZ, I. (in press). How working is defined: National contexts and demographic and organizational role influences. Journal of Occupational Behavior.

ENGLAND, G., \& MISUMI, J. (1986). Work centrality in Japan and the United Statcs. Journal of Cross-Cultural Psychology, 17, 339-416.

FURUKAWA, M. (1988). Cooperative education: A mode of in-house engineer development. Proceedings of the 1988 International Conference on Strategic R\&D Management (pp. 1-42). Ikebukuro, Tokyo, Japan: Japan Management Association.

GILLIGAN, C. (1982). In a different voice. Cambridge, MA: Harvard University Press.

HOFSTEDE, G. (1983). The cultural relativity of organizational practices and theories. Journal of International Business Studies, 14,75-89.

KOSHIRO, K. (1983). The quality of working life in Japanese factories. In T. Shirai (Ed.), Contemporary industrial relations in Japan. Madison, WI: University of Wisconsin Press. 
LEBRA, T. S. (1976). Japanese patterns of behavior. Honolulu, HA: University of Hawaii Press.

LEBRA, T. S. (1984). Japanese women: Constraint and fulfillment. Honolulu: University of Hawaii Press.

LINCOLN, J. R., \& KALLENBERG, A. L. (1990). Culture, control and commitment: $A$ study in work organization and work attitudes in the United States and Japan. New York: Cambridge University Press.

MAEHR, M., \& BRASKAMP, L. (1986). The motivation factor: A theory of personal investment. Lexington, MA: Lexington Press.

MCCLELLAND, D. (1961). The achieving society. Princeton, NJ: Van Nostrand.

MCLENDON, J. (1983). The office: Way station or blind alley? In D. W. Plath (Ed.), Work and lifecourse in Japan. Albany, NY: State University of New York Press.

NAOI, A., \& SCHOOLER, C. (1985). Occupational conditions and psychological functioning in Japan. American Journal of Sociology, 90, 729-752.

OSAKO, M. (1986). Japanese workers resist early retirement. Ageing International, 12, 33-34.

TURNER, J. S., \& HELMS, D. B. (1989). Contemporary adulthood. Chicago, IL: Holt, Rinehart \& Winston.

VOGEL, E. F. (1985). Comeback, case by case. New York: Simon \& Schuster.

VOGEL, E. F. (1991). Japan's new middle class (rev. ed.). Berkeley, CA: University of California Press.

\section{ABSTRACT TRANSLATIONS}

L'Inventoire d'Investissement Personnelle (IPI) a été donné à 522 travailleurs américains, afin de comparer leur motivation de travail et leur "concept de soi". On a formé onze "sub-scales," basés sur le modèle "IPI" et on les a trouvés par l'analyse de facteurs propres aux deux pays. On a fait des analyses discriminantes des "scale scores" des sujets par nationalité, sex, âge et métier. On a trouvé les conclusions suivantes: (1) que les travailleurs japonnais et américains mettent l'accent sur des aspects différents du travail et du "concept de soi", (2) que les Américaines et Japonnaises ont montré des profiles semblàbles les unes aux autres, (3) que les profiles de motivation pour les âges variés étaient différents pour les deux échantillons. Les résultats se rapportent à des recherches précédents sur les travailleurs japonnais et américains. (author-supplied abstract)

El Inventorio de Inversión Personal (IPI) fue administrado a 522 y a 746 trabajadores japoneses y norteamericanos respectivamente para comparar su motivación de trabajo y el concepto de si mismo. Se formaron once sub-escalas basadas sobre el modelo del IPI y se encontró por medio del análasis de factores que eran apropiadas para las muestras de ambos 
países. El análisis discernidor de la escala de resultados también se da en cuanto a la nacionalidad, sexo, nivel de alcance de trabajo y edad de cada individuo. Los resultados incluyen: 1) el muestrario de trabajadores japoneses y norteamericanos da énfasis a distintas variaciones de significado en la manera en que ellos perciben el trabajo y se perciben a si mismos, 2) el muestrario de mujeres japonesas y norteamericas mostraba perfiles similares la una a la otra, igual que dos sub-muestras de hombres, 3) el patrón de motivación para varias edades mostraba diferencias entre las dos muestras. Se relacionan los resultados a previa investigación de trabajadores japoneses y norteamericanos. (author-supplied abstract)

Note added in proof: This article is being published without benefit of the author's review of the proofs. The author's proofs were not available at the time of publication. 